\title{
Avaliação da conduta profissional em situações problemas relacionados ao exercício ético e legal da Odontologia
}
Professional conduct assessment in problem situations related to the ethical and legal Dentistry pratices

Evaluación de la conducta profesional en situaciones problemáticas relacionadas con el ejercicio ético y legal de la Odontologia

Luiz Fernando Lolli

ORCID: https://orcid.org/0000-0001-7426-5763 Universidade Estadual de Maringá, Brasil E-mail: profdrluizfernando@gmail.com

Natália de Souza Silva ORCID: https://orcid.org/0000-0002-9355-9406 Universidade Estadual de Maringá, Brasil E-mail: nssilva06@gmail.com

Marcela Fráguas Gélamo ORCID: https://orcid.org/0000-0002-3660-6747 Universidade Estadual de Maringá, Brasil E-mail: marcelafraguasg@gmail.com

Gabriel Quirino Dalpoz

ORCID: https://orcid.org/0000-0002-3873-9375 Universidade Estadual de Maringá, Brasil E-mail: gabrieldalpoz73@gmail.com

Gabriela Romanholo Fabiano

ORCID: https://orcid.org/0000-0002-4209-6456 Universidade Estadual de Maringá, Brasil E-mail: garomanholo@gmail.com

Caroline Hungaras Raimondi

ORCID: https://orcid.org/0000-0003-4946-3340 Universidade Estadual de Maringá, Brasil E-mail: raimondicarol28@gmail.com

Bárbara Vieira Pimentel ORCID: https://orcid.org/0000-0001-5549-8369 Universidade Estadual de Maringá, Brasil E-mail: barbarapimentel_4@hotmail.com

Isabela Hrecek Freitag ORCID: https://orcid.org/0000-0001-9407-2969 Universidade Estadual de Maringá, Brasil E-mail: isabelafreitag@gmail.com

Katia Cristina Toyokawa Sperandio ORCID: https://orcid.org/0000-0002-3986-6974 Universidade Estadual de Maringá, Brasil E-mail: katoyokawa@gmail.com

Maria Carolina Gobbi dos Santos Lolli ORCID: https://orcid.org/0000-0001-6582-3751 Universidade Estadual de Maringá, Brasil E-mail: profcarolinasantos@gmail.com

\begin{abstract}
Resumo
Historicamente, a formação em Odontologia tem sido predominantemente técnica, altamente voltada para a execução de procedimentos clínicos, ficando as abordagens de orientação profissional reservadas a momentos pontuais dos cursos. Objetivou-se com o presente estudo avaliar a conduta de estudantes do último ano da graduação e de pósgraduandos em Odontologia diante de situações problema relacionadas ao exercício ético e legal da profissão. Realizou-se um estudo quantitativo, observacional, descritivo e analítico, estruturado em um formulário contendo dez situações problema que poderiam ocorrer no dia a dia do exercício profissional. As situações versavam sobre abandono de tratamento, erro profissional, inversão do ônus da prova, prazo de contratos odontológicos, solicitação de retirada de documentação, relação ética, dados para confecção de cartão de visita, clínico geral realizando procedimento especializado, sigilo profissional e atestados odontológicos. A amostra consistiu em 88 participantes,
\end{abstract}


sendo 61 acadêmicos e 27 profissionais. A coleta ocorreu em duas instituições de ensino, sendo uma pública e uma privada. Os dados obtidos foram analisados nos programas EPI INFO e Bio Estat 5.0, considerando um nível de significância de 5\%. Os resultados demonstraram que das 10 situações-problema, a resposta considerada ideal prevaleceu em apenas 4 questões. Nas análises de associação verificou-se melhor desempenho de mulheres, vinculados ou egressos de instituição pública e com idade acima de 22 anos. Conclui-se que a conduta dos avaliados se mostrou variada diante das situações problemas, demonstrando não haver, na amostra considerada, uma padronização formativa relacionada ao exercício ético e legal da Odontologia.

Palavras-chave: Odontologia legal; Responsabilidade legal; Teoria ética.

\begin{abstract}
Historically, training in Dentistry has been predominantly technical, highly focused on the execution of clinical procedures, with professional guidance approaches reserved for specific moments of the courses. The objective of the present study was to evaluate the behavior of students in the final year of undergraduate and postgraduate students in Dentistry in the face of problem situations related to the ethical and legal exercise of the profession. A quantitative, observational, descriptive and analytical study was carried out, structured in a form containing ten problem situations that could occur in daily professional practice. The situations were about treatment abandonment, professional error, reversal of the burden of proof, term of dental contracts, request for withdrawal of documentation, ethical relationship, data for making a business card, general practitioner performing specialized procedure, professional secrecy and dental certificates. The sample consisted of 88 participants, being 61 academics and 27 professionals. The collection took place in two educational institutions, one public and one private. The data obtained were analyzed using the EPI INFO and Bio Estat 5.0 programs, considering a significance level of 5\%. The results showed that of the 10 problem situations, the answer considered ideal prevailed in only 4 questions. In the association analysis, there was a better performance of women, linked to or graduated from a public institution and aged over 22 years. It is concluded that the conduct of the evaluated ones was varied in the face of problem situations, demonstrating that, in the sample considered, there was no formative standardization related to the ethical and legal practice of Dentistry.
\end{abstract}

Keywords: Forensic dentistry; Legal liability; Ethical theory.

\title{
Resumen
}

Históricamente, la formación en Odontología ha sido predominantemente técnica, muy enfocada a la ejecución de procedimientos clínicos, con enfoques de orientación profesional reservados para momentos específicos de los cursos. El presente estudio tuvo como objetivo evaluar el comportamiento de los estudiantes del último año de pregrado y posgrado en Odontología frente a situaciones problemáticas relacionadas con el ejercicio ético y legal de la profesión. Se realizó un estudio cuantitativo, observacional, descriptivo y analítico, estructurado en un formulario que contiene diez situaciones problema que pueden presentarse en la práctica profesional diaria. Las situaciones fueron sobre abandono de tratamiento, error profesional, inversión de la carga de la prueba, vigencia de contratos odontológicos, solicitud de retiro de documentación, relación ética, datos para elaboración de tarjeta de presentación, médico general que realiza procedimiento especializado, secreto profesional y certificados odontológicos. La muestra estuvo conformada por 88 participantes, siendo 61 académicos y 27 profesionales. La colecta se realizó en dos instituciones educativas, una pública y otra privada. Los datos obtenidos fueron analizados mediante los programas EPI INFO y Bio Estat 5.0, considerando un nivel de significancia del 5\%. Los resultados mostraron que de las 10 situaciones problema, la respuesta considerada ideal prevaleció en solo 4 preguntas. En el análisis de asociación, hubo un mejor desempeño de las mujeres, vinculadas o egresadas de una institución pública y mayores de 22 años. Se concluye que la conducta de los evaluados fue variada frente a situaciones problema, demostrando que, en la muestra considerada, no hubo estandarización formativa relacionada con el ejercicio ético y legal de la Odontología.

Palabras clave: Odontología forense; Responsabilidad legal; Teoría ética.

\section{Introdução}

Ao exercer uma atividade profissional da área da saúde, além da natural condição de fazer o bem, empregar o melhor conhecimento e a melhor técnica, o dentista possui também a responsabilidade de responder pelos atos cometidos no exercício da profissão (Silva, et al., 2009).

A Odontologia brasileira possui uma prática predominante tecnicista e focada na clínica. Apesar das diretrizes curriculares nacionais (DCN's) apontarem a necessidade de um profissional generalista, com competências e habilidades diversas, inclusive relacionadas ao domínio de questões éticas e legais, os profissionais da área sentem dificuldades com questões rotineiras do consultório em termos éticos, legais e de orientação profissional como um todo (Brasil, 2021; Amorim \& Souza, 2010). Quando tais assuntos não são abordados na graduação, espera-se que os profissionais se apropriem do tema nos cursos de pós-graduação, tendo em vista que a disciplina de Ética e Legislação Odontológica é obrigatória em todos os 
cursos de especialização, cujas especialidades são reconhecidas pelo Conselho Federal de Odontologia (CFO), além de também estar presente em muitos cursos Stricto Sensu.

A formação eminentemente técnica e operacional, carente de aspectos de orientação profissional, somado ao fato da atual situação do mercado altamente competitivo, a atuação profissional muito focada na busca pela estética sem medir consequências ou ponderar aspectos correlatos, as falhas de formação dentre outros fatores, tem gerado substancial aumento no número de questionamentos judiciais e éticos contra dentistas. Além disso, o paciente odontológico está amparado por vasta legislação e encontra no Código de Defesa do Consumidor, uma série de direitos (Silva, et al., 2009).

São vários os procedimentos clínicos que podem gerar resultados adversos, seja por culpa do profissional ou por questões acidentais. Corrobora para isso o crescimento das novas abordagens em Odontologia, altamente voltadas para a estética, a exemplo da oferta de cursos de harmonização orofacial (Silva et al., 2021). A responsabilidade profissional surge quando o dever moral de não causar danos ao próximo no exercício da profissão é alterado ou prejudicado (Nogueira, et al., 2014). Quando se considera especialmente os profissionais da área da saúde, estes podem sofrer um enquadramento nos âmbitos civil, penal, ético e administrativo (Silva, 1997). Diante disso, no âmbito cível avalia-se o cometimento de um dano, este pressupõe o ressarcimento de prejuízos causados, que se expressa no pagamento de uma indenização. Criminalmente se avalia o cometimento de um crime, que após caracterizado de fato, o competente processo penal poderá levar à uma condenação. As penas neste sentido poderão ser detenção, reclusão e/ou multa (Lolli et al., 2013). Já os problemas éticos, arbitrados pelo CFO e pelos Conselhos Regionais de Odontologia (CRO's) estão relacionados à violação do Código de Ética Odontológica e, em casos de condenação, os profissionais podem sofrer sanções que variam de advertência confidencial até uma cassação do exercício profissional.

No âmbito administrativo, isto é, quando o profissional trabalha em uma instituição pública ou empresa privada, os atos irregulares se referem ao descumprimento de regimentos, estatutos e outros. Nestes casos, as punições são diversas, estão previstas em cada normativa e, na maioria das vezes, a penalidade maior é a exoneração ou demissão (Amorim \& Souza, 2010).

A carência de conhecimentos ou a inobservância de preceitos éticos e legais coloca o profissional em condição de vulnerabilidade no que diz respeito ao resguardo da sua atuação profissional na rotina de trabalho e causa fragilidade para a elaboração de uma defesa efetiva em eventuais processos que este venha a enfrentar (Brites, et al., 2016).

Com o intuito de contribuir na melhor compreensão de fatos ocorridos no cotidiano odontológico, esta pesquisa teve por objetivo avaliar a conduta, de tomada de decisão, de acadêmicos de graduação do último ano ou período e profissionais acadêmicos de pós-graduação diante de situações problema hipotéticas relacionadas aos aspectos éticos e legais da profissão.

\section{Metodologia}

O presente trabalho trata de um estudo observacional, quantitativo, transversal, descritivo e analítico sobre situações problemas da Odontologia no contexto legal e ético. Trata-se de uma proposta original, partindo de hipóteses metodológicas vastamente descritas na literatura, de acordo com Estrela (2018), Batista e Castro (2019), Pereira et. al. (2018), Marconi e Lakatos (2021) e Prodanov e Freitas (2013).

A amostra consistiu em 88 participantes, sendo acadêmicos do último ano do curso de Odontologia (n=61) e profissionais acadêmicos de pós-graduação $(\mathrm{n}=27)$. Os participantes foram discentes provenientes de duas instituições de ensino superior do município de Maringá-PR, uma pública e uma privada. Foi realizado um contato prévio com as instituições para permitir o acesso aos sujeitos da pesquisa e, somente após as autorizações dos dirigentes é que o contato efetivamente ocorreu. Todos os participantes foram devidamente instruídos sobre os propósitos desta pesquisa e assinaram o termo de consentimento livre e esclarecido (TCLE). 
A coleta de dados foi realizada por meio do livre preenchimento de um formulário estruturado contendo 10 situações problemas passíveis de ocorrer no cotidiano odontológico (Quadro 1).

Previamente à coleta de dados, o formulário foi aplicado em um teste piloto com 10 acadêmicos de Odontologia. Esta avaliação permitiu fazer ajustes, reestruturação dos temas, redução de tamanho do formulário e outros elementos e edição de palavras. Os acadêmicos participantes do estudo piloto não foram relacionados na amostra do estudo.

As variáveis consideradas nesta pesquisa foram agrupadas em variáveis de perfil e variáveis de análise. As variáveis de perfil foram: sexo, instituição de formação e idade dos participantes, já as variáveis de análise contemplaram as 10 situações problemas relacionadas a 10 temas previamente selecionados. Os temas foram: abandono de tratamento por parte do paciente, erro profissional, inversão do ônus da prova, prazo de contratos odontológicos, solicitação de retirada de documentação, relação ética com colega de profissão, dados para confecção de cartão de visita, clínico geral realizando procedimento especializado, sigilo profissional e atestados odontológicos.

Ao responder o formulário de análise, os entrevistados tiveram posicionamentos variados, muitos divergentes, o que gerou uma grande variedade de respostas. Para uma melhor organização dos dados, as respostas foram agrupadas em três padrões, sendo eles: ideal, aceito e não recomendado. Para realizar tal classificação, considerou-se como respostas ideais aquelas que apresentavam elementos chaves de acordo com a literatura, de acordo com cada tema abordado, tendo por base parâmetros extraídos da legislação odontológica e consideradas cinco obras da área de Odontologia Legal e Deontologia (Vanrell, 2019; Daruge, et al., 2017; Silva, 1997; Silva, 2010; Couto, 2011). Já na categoria "aceito", foram incluídas respostas que contemplavam parcialmente o que era recomendado para cada situação. Por fim, respostas contrárias do embasamento científico, foram classificadas como "não recomendadas".

Os dados obtidos foram transcritos em planilhas do Microsoft Excel®. Em seguida passaram por uma reorganização no programa Epi Info® (Dean, et al., 2002) as quais variáveis de análise foram associadas às variáveis de perfil. Os resultados foram apresentados de forma descritiva e analítica. As análises de associação entre variáveis de perfil e de análise foram realizadas com a utilização do teste Qui-quadrado $\left(x^{2}\right)$ de Partição, considerando um nível de significância de 5\%. Para as análises foi utilizado o software Bioestat 5.0 (Ayres, et al., 2007).

Esse estudo foi aprovado pelo Comitê de Ética e Pesquisa com Seres Humanos da Universidade Estadual de Maringá tendo o parecer contido no Protocolo CAAE: 18609019.8.1001.0104, em 19 de setembro de 2019, com presidente Ricardo César Gardiolo. 
Quadro 1: Formulário sobre situações problema relacionadas ao exercício ético e legal da odontologia. Maringá, 2020.

Situação 01: Um paciente seu começa a faltar repentinamente e sem aviso prévio. Você entra em contato (Whatsapp, Email, telefone) e não obtém retorno. O que você faz?

Situação 02: Atendendo a paciente encaminhado, você extraiu equivocadamente o dente 15 no lugar do 14, que tinha indicação ortodôntica. O que fazer nesta situação?

Situação 03: Ao realizar um tratamento endodôntico, ocorre acidentalmente e fratura de uma lima dentro do canal radicular. Você tenta remover e não consegue. O que você faz?

Situação 04: Suponha que você receba uma citação do Poder Judiciário comunicando uma ação (processo) movido por um paciente. Na petição, ele solicita inversão do ônus da prova. O que você faz?

Situação 05: Um paciente em tratamento ortodôntico de 38 meses está irritado com a demora para a finalização do caso. O contrato está vencido e ele solicita retirar o aparelho e ainda quer levar o prontuário e toda a documentação de diagnóstico (panorâmica, telerradiografia e modelos). Diante disso, qual a sua conduta?

Situação 06: Um paciente vem para reabilitação bucal. Você vê a necessidade de uma prótese fixa com núcleo em um dente que não possui tratamento endodôntico. Ao propor a endo, o paciente alega já ter feito recentemente. O que você faz?

Situação 07: Você acabou de se formar e vai atuar como pessoa física. Ao elaborar seu cartão de visitas, quais dados você colocaria?

Situação 08: É lícito o clínico geral realizar procedimentos de especialidades?

Situação 09: Ao realizar a anamnese, uma paciente, menor de idade, te relata ser portadora de HIV e comenta que seus pais não sabem. Qual seria a conduta adequada neste caso?

Situação 10: O pai acompanha o filho à consulta. No final do atendimento o pai solicita um atestado para justificar a falta dele ao emprego e do filho ao colégio. Como você procede?

Fonte: Autores (2020).

\section{Resultados e Discussão}

A Figura 1 demonstra dados descritivos das respostas dadas às 10 situações problemas, considerando a classificação ideal, aceita, e não recomendada. Verifica-se que a resposta "ideal" só prevaleceu em 4 questões. A situação "aceita" prevaleceu em 5 questões e o "não recomendado" em apenas 1 questão. 
Research, Society and Development, v. 11, n. 3, e21911326384, 2022

(CC BY 4.0) | ISSN 2525-3409 | DOI: http://dx.doi.org/10.33448/rsd-v11i3.26384

Figura 1: Descritivo de respostas da amostra geral acerca de situações problema relacionadas ao exercício ético e legal da Odontologia. Maringá, 2020.

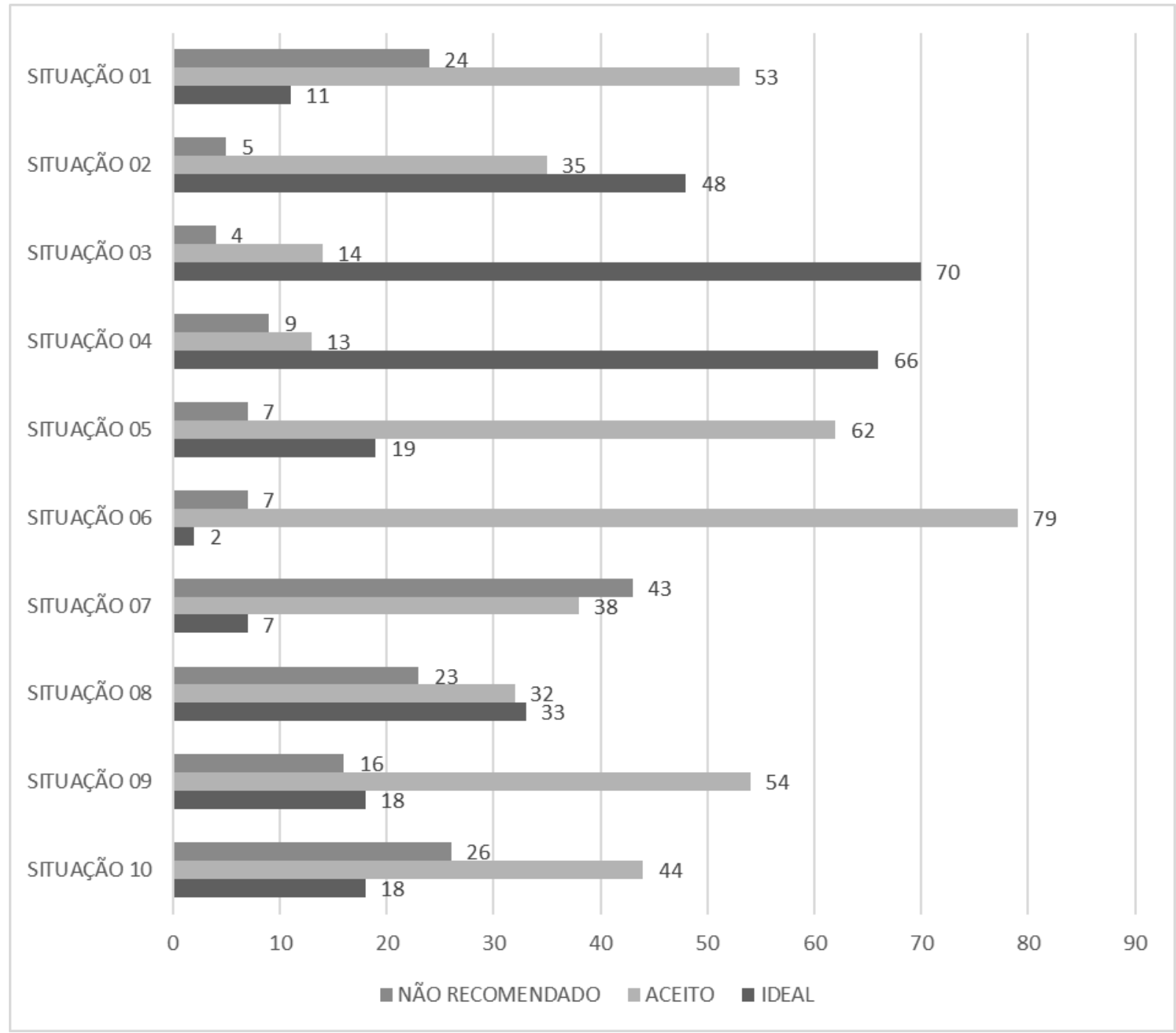

Fonte: Autores (2020).

A Tabela 1 retrata a associação entre as variáveis de análise e de perfil. Verificou-se que houve associação estatística da situação 1 com instituição e idade. Pessoas provenientes de instituição pública tiveram mais respostas aceitas e menos "não recomendadas". Pessoas acima dos 22 anos souberam mais como proceder quando o paciente começa a faltar repentinamente. 
Tabela 1: Associação entre variáveis de análise e de perfil na pesquisa sobre situações problemas relacionados ao exercício ético e legal da odontologia. Maringá, 2020.

\begin{tabular}{|c|c|c|c|c|c|c|c|c|c|c|}
\hline \multirow{2}{*}{\multicolumn{2}{|c|}{ ASSOCIAÇÃO DE VARIÁVEIS }} & \multicolumn{3}{|c|}{ SEXO } & \multicolumn{3}{|c|}{ INSTITUIÇÃO } & \multicolumn{3}{|c|}{ IDADE } \\
\hline & & FEM & MAS & P-valor & PRIVADA & PÚBLICA & P-valor & ATÉ 22a. & $>22 \mathrm{a}$ & P-valor \\
\hline \multirow{3}{*}{ S01 } & IDEAL & 9 & 2 & - & 3 & 8 & - & 0 & 11 & - \\
\hline & ACEITO & 41 & 12 & 0,7386 & 32 & 21 & 0,0378* & 20 & 33 & 0,0200* \\
\hline & NÃO RECOMENDADO & 20 & 4 & 0,5896 & 21 & 3 & $0,0044 *$ & 15 & 9 & 0,0076* \\
\hline \multirow{3}{*}{ S02 } & IDEAL & 40 & 7 & - & 31 & 17 & - & 19 & 29 & - \\
\hline & ACEITO & 28 & 8 & 0,4120 & 21 & 14 & 0,6682 & 13 & 22 & 0,8225 \\
\hline & NÃO RECOMENDADO & 2 & 3 & $0,0240 *$ & 4 & 1 & 0,4335 & 3 & 2 & 0,3413 \\
\hline \multirow{3}{*}{ S03 } & IDEAL & 59 & 7 & - & 46 & 24 & - & 27 & 43 & - \\
\hline & ACEITO & 7 & 11 & $<0.0001 *$ & 6 & 8 & 0,1046 & 5 & 9 & 0.8420 \\
\hline & NÃO RECOMENDADO & 4 & 0 & 0,2992 & 4 & 0 & 0,1218 & 3 & 1 & 0,1406 \\
\hline \multirow{3}{*}{ S04 } & IDEAL & 54 & 12 & - & 45 & 21 & - & 29 & 37 & - \\
\hline & ACEITO & 10 & 3 & 0,6892 & 2 & 11 & 0,0003* & 1 & 12 & $0,0147 *$ \\
\hline & NÃO RECOMENDADO & 6 & 3 & 0,3120 & 9 & 0 & $0,0167 *$ & 5 & 4 & 0,3072 \\
\hline \multirow{3}{*}{ S05 } & IDEAL & 16 & 3 & - & 12 & 7 & - & 10 & 9 & - \\
\hline & ACEITO & 48 & 14 & 0,5208 & 37 & 25 & 0,7826 & 20 & 42 & 0,1124 \\
\hline & NÃO RECOMENDADO & 6 & 1 & 0,6732 & 7 & 0 & 0,0371* & 5 & 2 & 0,0745 \\
\hline \multirow{3}{*}{ S06 } & IDEAL & 63 & 16 & - & 1 & 1 & - & 1 & 1 & - \\
\hline & ACEITO & 2 & 0 & 0,4831 & 49 & 30 & 0,7270 & 32 & 47 & 0,7865 \\
\hline & NÃO RECOMENDADO & 5 & 2 & 0,5789 & 6 & 1 & 0,2056 & 2 & 5 & 0,5279 \\
\hline \multirow{3}{*}{ S07 } & IDEAL & 6 & 1 & - & 1 & 6 & - & 0 & 7 & - \\
\hline & ACEITO & 32 & 6 & 0,9278 & 29 & 9 & $0,0017 *$ & 18 & 20 & 0,0186* \\
\hline & NÃO RECOMENDADO & 32 & 11 & 0,2438 & 26 & 17 & 0,5455 & 17 & 26 & 0,9645 \\
\hline \multirow{3}{*}{ S08 } & IDEAL & 26 & 7 & - & 18 & 15 & - & 11 & 22 & - \\
\hline & ACEITO & 26 & 6 & 0,8057 & 22 & 13 & 0,4731 & 13 & 19 & 0,5482 \\
\hline & NÃO RECOMENDADO & 18 & 5 & 0,8590 & 19 & 4 & 0,0389* & 11 & 12 & 0,3585 \\
\hline \multirow{3}{*}{ S09 } & IDEAL & 16 & 2 & - & 5 & 13 & - & 2 & 16 & - \\
\hline & ACEITO & 40 & 14 & 0,1772 & 38 & 16 & 0,0011* & 25 & 29 & 0,0083* \\
\hline & NÃO RECOMENDADO & 14 & 2 & 0,3832 & 13 & 3 & 0,1054 & 8 & 8 & 0,3554 \\
\hline \multirow{3}{*}{ S10 } & IDEAL & 15 & 3 & - & 13 & 5 & - & 8 & 10 & - \\
\hline & ACEITO & 33 & 11 & 0,4603 & 26 & 18 & 0,3292 & 16 & 28 & 0,5551 \\
\hline & NÃO RECOMENDADO & 22 & 4 & 0,4451 & 17 & 9 & 0,8253 & 11 & 15 & 0,7530 \\
\hline
\end{tabular}

Significância estatística $(*)$ para $p<0,05$. Test qui-quadrado $\left(\mathrm{X}^{2}\right)$ de partição. Fonte: Autores (2020).

As situações 2 e 3 foram estatisticamente associadas ao sexo. Pessoas do sexo feminino se saíram melhor na condução de casos de extração de um dente errado e de fratura de uma lima no interior do canal radicular. A situação 4 esteve associada à instituição e idade. Os de instituição pública se saíram melhor nas providências quanto à tomada de decisões diante de um processo com inversão do ônus da prova. Assim também ocorreu para os indivíduos de mais idade. A situação 5 teve associação com Instituição. Os provenientes das púbicas tiveram melhor condução quando da necessidade de retirar o aparelho ortodôntico e quando solicitada a documentação do consultório.

A situação 6 não teve associação estatística. Já a 7 se associou com instituição e idade. Pessoas de instituição pública e com mais idade souberam melhor o que colocar num cartão de visitas odontológico. A situação 8 esteve associada à instituição. Neste sentido, o pessoal de instituição pública teve melhor padrão de resposta diante da indagação do clínico geral realizar procedimentos de especialidade. A situação 9 se associou com instituição e idade. Provenientes das públicas e com idade maior apresentaram condução mais adequada diante da constatação de paciente com HIV e cuja informação deve ser notificada.

A Tabela 2 mostra o comparativo do padrão de respostas dos acadêmicos de graduação e de pós-graduação. Observase que o grupo da pós-graduação obteve um melhor resultado em sete das 10 situações apresentadas no questionário. Ao 
refazer essa análise através do outro extremo, ou seja, pela porcentagem de respostas categorizadas como "não recomendada", observa-se que o grupo da graduação obteve uma maior quantidade de respostas nessa categoria em 9 das situações, sendo que em somente uma - situação 10 - ambos os grupos apresentaram o mesmo resultado para tal perfil de resposta.

A primeira questão (S01) abordava uma situação na qual um paciente passa a faltar no consultório odontológico sem aviso prévio. Diante disso, o profissional realizava tentativas de contato via meios convencionais, como telefone, whatsApp, $e$ mail, porém sem resposta.

Ao analisar a literatura acerca do assunto, o Código de Ética Odontológica (CEO), traz em seu Artigo 11, inciso VI, que:

\section{Art 11. Constitui infração ética}

"abandonar paciente, salvo por motivo justificável, circunstância em que serão conciliados os honorários e que deverá ser informado ao paciente ou ao seu responsável legal de necessidade da continuidade do tratamento”.

Deste modo, na situação acima apresentada, Paranhos, et al. (2011), sugere que, na ausência do paciente do consultório por mais de 30 dias, seja realizado contato telefônico e se ainda assim permanecer, que seja enviada uma carta registrada, guardando uma via anexada ao prontuário, devendo estar claro na carta a importância do tratamento e que sua ausência acarretará abandono do mesmo. Sendo assim, considerou-se dentro do perfil ideal, respostas as quais retratavam o envio de carta registrada ao paciente, após tentativa falha de contato por outros métodos. As respostas que relatavam o preenchimento do prontuário com as faltas do paciente e a insistência no contato por vias convencionais, porém, não mencionavam a carta registrada, foram classificadas como aceitas. Já as respostas que mencionavam apenas o desligamento automático do paciente ou a falta de contato com ele, foram então agrupadas como não recomendável.

Tabela 2: Comparativo do padrão de respostas entre acadêmicos da graduação e da pós-graduação acerca de situações problemas relacionados ao exercício ético e legal da odontologia. Maringá, 2020.

\begin{tabular}{|c|c|c|c|c|c|}
\hline \multicolumn{2}{|r|}{ COMPARATIVO } & \multicolumn{2}{|c|}{$\begin{array}{c}\text { GRADUAÇÃO } \\
(n=61)\end{array}$} & \multicolumn{2}{|c|}{ PÓS-GRADUAÇÃO $(n=27)$} \\
\hline & & $\mathbf{n}$ & $\%$ & $\mathbf{n}$ & $\%$ \\
\hline \multirow{3}{*}{ Q01 } & IDEAL & 3 & $5 \%$ & 8 & $30 \%$ \\
\hline & ACEITO & 36 & $59 \%$ & 17 & $63 \%$ \\
\hline & NÃO RECOMENDADO & 22 & $36 \%$ & 2 & $7 \%$ \\
\hline \multirow{3}{*}{ Q02 } & IDEAL & 34 & $56 \%$ & 14 & $52 \%$ \\
\hline & ACEITO & 23 & $38 \%$ & 12 & $44 \%$ \\
\hline & NÃO RECOMENDADO & 4 & $6 \%$ & 1 & $4 \%$ \\
\hline \multirow{3}{*}{ Q03 } & IDEAL & 47 & $77 \%$ & 23 & $85 \%$ \\
\hline & ACEITO & 10 & $16 \%$ & 4 & $15 \%$ \\
\hline & NÃO RECOMENDADO & 4 & $7 \%$ & 0 & $0 \%$ \\
\hline \multirow{3}{*}{ Q04 } & IDEAL & 50 & $82 \%$ & 16 & $60 \%$ \\
\hline & ACEITO & 4 & $7 \%$ & 9 & $33 \%$ \\
\hline & NÃO RECOMENDADO & 7 & $11 \%$ & 2 & $7 \%$ \\
\hline \multirow{3}{*}{ Q05 } & IDEAL & 16 & $26 \%$ & 3 & $11 \%$ \\
\hline & ACEITO & 38 & $62 \%$ & 24 & $89 \%$ \\
\hline & NÃO RECOMENDADO & 7 & $12 \%$ & 0 & $0 \%$ \\
\hline \multirow{3}{*}{ Q06 } & IDEAL & 1 & $2 \%$ & 1 & $4 \%$ \\
\hline & ACEITO & 55 & $90 \%$ & 24 & $89 \%$ \\
\hline & NÃO RECOMENDADO & 5 & $8 \%$ & 2 & $7 \%$ \\
\hline
\end{tabular}




\begin{tabular}{|c|c|c|c|c|c|}
\hline \multirow{3}{*}{ Q07 } & IDEAL & 1 & $2 \%$ & 6 & $22 \%$ \\
\hline & ACEITO & 27 & $44 \%$ & 11 & $41 \%$ \\
\hline & NÃO RECOMENDADO & 33 & $54 \%$ & 10 & $37 \%$ \\
\hline \multirow{3}{*}{ Q08 } & IDEAL & 18 & $30 \%$ & 15 & $55 \%$ \\
\hline & ACEITO & 24 & $39 \%$ & 8 & $30 \%$ \\
\hline & NÃO RECOMENDADO & 19 & $31 \%$ & 4 & $15 \%$ \\
\hline \multirow{3}{*}{ Q09 } & IDEAL & 6 & $10 \%$ & 12 & $44 \%$ \\
\hline & ACEITO & 42 & $69 \%$ & 12 & $45 \%$ \\
\hline & NÃO RECOMENDADO & 13 & $21 \%$ & 3 & $11 \%$ \\
\hline \multirow{3}{*}{ Q10 } & IDEAL & 10 & $17 \%$ & 8 & $30 \%$ \\
\hline & ACEITO & 33 & $54 \%$ & 11 & $41 \%$ \\
\hline & NÃO RECOMENDADO & 18 & $29 \%$ & 8 & $29 \%$ \\
\hline
\end{tabular}

Fonte: Autores (2020).

Em seguida (S02), os entrevistados foram indagados sobre um caso em que o profissional extrai, equivocadamente, o dente errado de um paciente que viera encaminhado por outro colega.

Em uma situação como esta, é de extrema importância que o cirurgião-dentista comunique o erro ao paciente, se coloque à disposição para buscar alternativas de sanar o problema e registre o ocorrido no prontuário, juntamente com a descrição da postura do profissional e solicite a assinatura do paciente. É de bom tom que o cirurgião dentista assuma as custas do tratamento adequado ao caso. Cabe citar que, segundo o Art. 949 do Código Civil Brasileiro, no caso de lesão, ou outra ofensa à saúde, o ofensor, neste caso o cirurgião dentista, indenizará o ofendido das despesas do tratamento, além de algum outro prejuízo que este tenha sofrido. Em outras palavras, caso haja petição do paciente em juízo (processo civil), é bem provável que haja uma condenação do profissional. Além disso, o Art. 129 do Código Penal Brasileiro versa sobre o crime de lesão corporal, situação que poderia ser enquadrada o caso em questão, dando vazão a uma ação penal. Obviamente o intuito é evitar qualquer uma destas possibilidades. Assim exposto, considerou-se como perfil de resposta ideal aquela na qual o dentista se mostra transparente e diligente em reação ao ocorrido, manifestando a conduta de arcar com os custos para a resolução do problema. Para esta situação, classificou-se como respostas ideais as que afirmavam que a conduta ideal seria a de informar o erro ao paciente, além de anotar no prontuário o ocorrido, solicitando, juntamente, a assinatura do paciente, demonstrando o conhecimento do mesmo sobre a situação, além de arcar com as consequências do erro, como por exemplo a instalação de implante ou reposicionamento ortodôntico. Respostas as quais relatavam somente que o profissional deveria arcar com as consequências, enquadraram-se como aceitas, visto que não retratavam a vertente relacionada ao preenchimento do prontuário. Já aquelas que não apresentassem nenhuma das condutas acima citadas, classificou-se como não recomendadas.

$\mathrm{Na}$ questão seguinte (S03), os entrevistados foram questionados sobre qual atitude tomar diante da situação de fratura de lima dentro do canal radicular. Em situações como esta, de antemão, é de extrema importância que o profissional possua uma documentação odontológica completa, na qual o paciente, antes de iniciar o tratamento, tenha consentido, ciente dos riscos e complicações do procedimento, já possuindo assim o profissional uma proteção preliminar, visto que então, somente seria classificado como negligência, no caso de falta de informação do dentista para com o paciente (Schwartz, 1995). Desta forma, é importante também que o cirurgião dentista documente todo o ocorrido no prontuário solicitando assinatura do paciente e proponha o acompanhamento do caso para se decidir a melhor conduta futura.

Para este caso, tomou-se como ideal a conduta que retratava o preenchimento do prontuário relatando a situação, juntamente com a assinatura do paciente e a postura diligente e atenciosa do profissional em acompanhar o caso. Agruparam-se como aceitas as respostas que continham o acompanhamento da situação bem como o aviso ao paciente, porém, não 
afirmavam com clareza acerca do preenchimento da ficha clínica. Por fim, classificaram-se como condutas não aceitas as quais divergiam das situações acima descritas.

A questão de número 04 (S04) abordou uma situação onde o profissional estaria sendo processado pelo paciente, sendo que, este solicitara a inversão do ônus da prova, tendo sido concedida pelo juiz. Quando se trata dessa questão, é importante ter em mente que o paciente é um consumidor, o profissional um prestador de serviços, fatos que enquadram a relação jurídica no Código de Defesa do Consumidor, no qual, em seu Art. $6^{\circ}$ traz que:

Art. $6^{\circ}$ São direitos básicos do consumidor:

VIII - a facilitação da defesa de seus direitos, inclusive com a inversão do ônus da prova, a seu favor, no processo civil, quando, a critério do juiz, for verossímil a alegação ou quando for ele hipossuficiente, segundo as regras ordinárias de experiências;

O ônus da prova é a necessidade de quem acusa provar a acusação. Em casos de ações de responsabilidade civil, principalmente em situações de prestação de serviços técnicos, como na Odontologia, observa-se a dinâmica do ônus probatório, sendo atribuído pelo juiz, em determinados casos, o encargo de prova à parte que detiver conhecimento técnico ou informações específicas sobre os fatos, decretando-se então a inversão do ônus da prova (Junior, 2015).

No caso em questão, a situação ideal deve necessariamente considerar reunir as provas documentais (prontuário) do tratamento. Dito isso, as respostas que continham tal informação agruparam-se como ideal, mesmo que acompanhadas de outras condutas. Já os entrevistados que responderam que a conduta tomada seria a de procurar ajuda profissional, como um advogado e/ou um assistente técnico, classificou-se como aceita, enquanto as respostas que não continham nenhuma dessas condutas foram agrupadas como não recomendadas.

A questão de número 5 (S05), apresentava uma situação em que um paciente de tratamento ortodôntico, insatisfeito com a demora da finalização do tratamento, que já se perdurava por 38 meses, pedia a interrupção do mesmo, bem como a retirada de sua documentação de diagnóstico e prontuário. Em casos como este, é importante salientar que o contrato de prestação de serviços odontológicos é um documento que, apesar de não obrigatório, é altamente desejável para integrar o prontuário odontológico, o qual servirá como proteção tanto do profissional como do paciente (Daruge, et al, 2017). Quanto à duração do contrato, é necessário que nele esteja estipulado uma previsão estimada de tempo do tratamento, entretanto, o Código Civil Brasileiro determina um prazo máximo de validade para contratos de prestação de serviços:

"Art. 598 - A prestação de serviço não se poderá convencionar por mais de quatro anos, embora o contrato tenha por causa o pagamento de dívida de quem o presta, ou se destine à execução de certa e determinada obra. Neste caso, decorridos quatro anos, dar-se-á por findo o contrato, ainda que não concluída a obra."

Deste modo então, tem-se que o contrato odontológico tem validade máxima de 48 meses, porém, nada impede que após esse prazo, um novo contrato seja estabelecido se desejado por ambas as partes. Sendo assim, no caso acima apresentado, o contrato ainda se apresentava dentro do prazo máximo estipulado pelo CCB, porém, é de direito de ambas as partes realizar a rescisão do contrato a qualquer momento, observando suas condições e cláusulas.

No que diz respeito à solicitação de entrega dos documentos de diagnóstico e do prontuário ao paciente, se faz necessário entender que, sendo o prontuário o resultado de informações colhidas pelo cirurgião-dentista aliadas aos seus conhecimentos, é justo considerar o documento como uma produção intelectual do profissional, sendo então este o titular dos direitos documentais (Peres et al., 2007). Por outro lado, o Código de Ética Odontológica aponta em seu Capítulo III (Deveres Fundamentais): 
“Art. $5^{\circ}$ Constituem deveres fundamentais dos profissionais e entidades da Odontologia (...) XVI) garantir ao seu paciente ou responsável legal, acesso a seu prontuário, sempre que for expressamente solicitado, podendo conceder cópia do documento, mediante recibo de entrega".

Deste modo então, sendo o prontuário pertinente a ambas as partes, quando feita a solicitação de retirada por parte do paciente, aconselha-se que o cirurgião-dentista realize uma cópia de toda a documentação e entregue ao solicitante, ficando então com a documentação original arquivada para uma eventual necessidade futura. Além disso, é de suma importância que o profissional realize um recibo de recebimento o qual deve ser assinado pelo paciente. No caso dos exames complementares, há de se verificar se o paciente pagou por eles ou se foram realizados pelo profissional sem custos adicionais para o paciente. $\mathrm{Na}$ primeira hipótese os originais são devolvidos ao paciente. Na segunda ficam com o profissional e cópias ao paciente são providenciadas.

Em casos como este, é primordial, primeiramente, que o profissional estabeleça um termo de ciência o qual deve ser assinado pelo paciente, orientando que o seu tratamento ainda não está finalizado. Somado a isso, se faz necessária a entrega de uma cópia dos documentos ao paciente. Assim sendo, considerou-se como conduta ideal aquelas as quais citavam a entrega da documentação ao paciente somado à assinatura de um termo ou assinatura no prontuário com anotação de tal situação. Estabeleceu-se como conduta aceita aquela que citava uma das duas medidas acima citadas. Por fim, aquelas respostas as quais não continham nenhuma dessas informações entendeu-se como não recomendadas.

Na condição de número 6 (S06), é relatada uma situação onde um paciente, necessitando de uma prótese fixa, necessitaria também realizar o tratamento endodôntico deste dente. Porém, o mesmo alegava já o ter feito anteriormente a endodontia do elemento com outro profissional, fato que não fora observado. Em situações como esta, o Código de Ética Odontológica traz que:

Art.13. Constitui infração ética:

VI- Criticar erro técnico científico de colega ausente, salvo por meio de representação ao Conselho Regional;

Fica claro que o profissional não deve expor ou julgar o colega ausente. Assim, em situações como esta, deve se fazer o máximo possível para contornar a situação, podendo posteriormente fazer uma representação ao Conselho de Odontologia. Antes de representar contra o profissional, é de boa índole entrar em contato com o mesmo e relatar a situação. Outro ponto é que o paciente pode ter se equivocado em relação ao dente que foi tratado outro equívoco ocorrido na relação profissionalpaciente anterior.

Diante do exposto, a conduta para situações como estas seria a de não difamar o colega o qual atendeu anteriormente o paciente, havendo a possibilidade de reportar juntamente ao Conselho o erro. Deste modo, as respostas que julgavam inadequado difamar o profissional para o paciente, classificaram-se como ideais, enquanto aquelas que não afirmavam isso, porém, alegavam que conversariam com o paciente sobre o caso no sentido de orientar agruparam-se como aceitas. Por fim, aquelas que não se enquadravam em nenhum desses padrões, foram consideradas não recomendadas.

$\mathrm{Na}$ situação seguinte (S07) foi analisado o conhecimento dos entrevistados a respeito do Código de Ética Odontológica, mais exatamente sobre propaganda, abordando como assunto principal dados de cartão de visita para pessoa física.

Sobre o tema, tem-se disposto no CEO, Capítulo XVI, Artigo 43:

Art.43. Na comunicação e divulgação é obrigatório constar o nome e o número de inscrição da pessoa física ou jurídica, bem como o nome representativo da profissão de cirurgião-dentista e também das demais profissões auxiliares regulamentadas. No caso de pessoas jurídicas, também o nome e o número de inscrição do responsável técnico. 
$\S 1^{\circ}$. Poderão ainda constar na comunicação e divulgação:

$\boldsymbol{I}$ - áreas de atuação, procedimentos e técnicas de tratamento, desde que precedidos do título da especialidade registrada no Conselho Regional ou qualificação profissional de clínico geral. Áreas de atuação são procedimentos pertinentes às especialidades reconhecidas pelo Conselho Federal;

$\boldsymbol{I I}$ - as especialidades nas quais o cirurgião dentista esteja inscrito no Conselho Regional;

III - os títulos de formação acadêmica "stricto sensu" e do magistério relativos à profissão;

$\boldsymbol{I V}$ - endereço, telefone, faz, endereço eletrônico, horário de trabalho, convênios, credenciamentos, atendimentos domiciliar e hospitalar;

$\boldsymbol{V}$-logomarca elou logotipo;

$\boldsymbol{V I}$ - a expressão 'clínico geral', pelos profissionais que exerçam atividades pertinentes à Odontologia decorrentes de conhecimentos adquiridos em curso de graduação ou em cursos de pós-graduação.

Feita a análise do citado artigo do Código de Ética, observa-se então a obrigatoriedade dos itens: Nome, número de inscrição no Conselho e o nome representativo da profissão, ou seja, Cirurgião Dentista, podendo ainda serem apresentadas outras informações, como títulos e procedimentos, porém estes sem caráter de obrigatoriedade. Ao analisar as respostas dos entrevistados, pôde-se perceber que muitos, ao invés de colocar o nome representativo da profissão, informaram que colocariam a qualificação de "clínico geral", o que gerou um certo questionamento sobre se isso seria uma confusão entre os títulos que os mesmos apresentam. Considerou-se como resposta ideal da questão, as que apresentavam todos os dados obrigatórios. Foram aceitas as que apresentavam, ao menos, as informações nome e número de inscrição e outras informações possíveis, porém não obrigatórias, somadas ao título de clínico geral, devido à provável confusão. Já aquelas que não continha nenhuma das titulações, agrupou-se como não recomendada.

Ao expor a situação de número 8 (S08), foi questionado aos entrevistados se o clínico geral poderia realizar procedimentos de especialidades. Destaca-se que, para responder tal pergunta, deve-se relacionar a Lei nº5.081 que regulamenta Odontologia no Brasil. No que diz respeito a esse aspecto, a presente Lei aponta que:

\section{Art. $6^{\circ}$ Compete ao cirurgião-dentista:}

I - praticar todos os atos pertinentes a Odontologia, decorrentes de conhecimentos adquiridos em curso regular ou em cursos de pós-graduação;

Tem-se então que o profissional da Odontologia pode executar qualquer procedimento desde que ele tenha conhecimento prévio obtido em curso de graduação ou pós-graduação. Desta forma, se o procedimento foi aprendido no curso de graduação ou em cursos de pós-graduação (mesmo que seja uma atualização ou aperfeiçoamento), o profissional, mesmo sem especialização na determinada área, está pela lei, apto a executar o procedimento. Com isso, tomou-se como conduta ideal as que afirmavam concordar com a realização do procedimento por clínico geral se o mesmo tivesse conhecimento prévio acerca do assunto, como aceita as que simplesmente afirmavam ser correto a execução dos procedimentos, mesmo sem detalhar o conhecimento prévio, por mais que isso seja imperativo e como não recomendada aquelas que afirmavam não ser correto.

A questão de número 9 (S09) abordou uma situação na qual uma paciente menor de idade relata na anamnese ser portadora de HIV, entretanto, alega que seus pais não sabem do caso. Para discutir a conduta ideal desse caso, dois pontos devem ser elencados, o primeiro seria a questão do sigilo profissional e a segunda a obrigatoriedade da notificação compulsória pelo cirurgião-dentista.

Em 30 de outubro de 1975, foi criada a Lei $n^{\circ}$ 6.259, a qual dispõe sobre a organização das ações de Vigilância Epidemiológica, sobre o Programa Nacional de Imunizações e estabelece normas relativas à notificação compulsória de doenças. Na presente Lei tem-se que: 
Art $8^{\circ}$ É dever de todo cidadão comunicar à autoridade sanitária local a ocorrência de fato, comprovado ou presumível, de caso de doença transmissível, sendo obrigatória a médicos e outros profissionais de saúde no exercício da profissão, bem como aos responsáveis por organizações e estabelecimentos públicos e particulares de saúde e ensino a notificação de casos suspeitos ou confirmados das doenças relacionadas em conformidade com o artigo $7^{\circ}$.

Somado a isso, o Ministério da Saúde estabeleceu a Portaria de Consolidação nº 4 de 28 de setembro de 2017, a qual estabelece a lista de doenças que tem sua comunicação obrigatória pelos profissionais da saúde, sendo algumas delas: Acidente de trabalho com exposição a material biológico; Dengue; Varíola; Ebola; Doença aguda pelo vírus Zika; Febre Amarela; HIV/AIDS - Infecção pelo Vírus da Imunodeficiência Humana ou Síndrome da Imunodeficiência Adquirida; Sífilis; Tétano; Tuberculose; Violência doméstica e outras violências.

O segundo ponto é sobre o desconhecimento dos pais sobre o fato. Acerca disso, o Código de Ética Odontológica traz em seu Capítulo VI - Do Sigilo Profissional:

\author{
Art. 14. Constitui infração ética: \\ I - revelar, sem justa causa, fato sigiloso de que tenha conhecimento em razão do exercício de sua profissão; \\ §Parágrafo Único. Compreende-se como justa causa, principalmente: \\ I- notificação compulsória de doença; \\ II - colaboração com a justiça nos casos previstos em lei; \\ III - perícia odontológica nos seus exatos limites; \\ $\boldsymbol{I V}$ - estrita defesa de interesse legítimo dos profissionais inscritos; \\ $V$ - revelação de fato sigiloso ao responsável pelo incapaz.
}

Assim, observa-se que o profissional realizar a notificação compulsória não só é obrigatória como também é uma justa causa para romper o sigilo profissional. Além disso, tem-se que, revelar fato sigiloso ao responsável também é uma situação de justa causa, mas neste caso a revelação não é obrigatória, é apenas possível por ser justa causa, ficando então a critério do profissional contar ou não aos pais. É importante salientar que o profissional atento poderá conhecer um pouco da relação que se estabelece entre a filha os pais, as condições de saúde da paciente e outros dados que sejam parâmetros para decidir quanto à revelação ou não.

Analisa-se então que a obrigatoriedade neste caso envolve a notificação compulsória, por isso, a conduta ideal dessa situação seria a que citava a realização da mesma. Aquelas respostas que não a citavam, mas recomendavam que deveria ser feita uma orientação à paciente quanto a sua saúde ou ainda a comunicação aos responsáveis legais classificou-se como aceitas, e, por fim, aquelas que não citavam nenhuma das duas alternativas agruparam-se como não recomendada.

Na última situação (S10) do questionário aplicado, foi abordado o atestado odontológico. Apresentou-se uma situação hipotética onde um pai, que acompanhava o filho na consulta odontológica, solicitava, ao término, atestado para ambos. Almeida (2004) salienta que o atestado é o documento odontolegal mais produzido pelo cirurgião dentista. A emissão está assegurada pela Lei n ${ }^{\circ} 5.081$, de 24 de agosto de 1966, inclusive para justificar faltas ao emprego".

No que se diz respeito ao fornecimento de documentos, em específico os atestados, a conduta ideal seria fornecer ao paciente um atestado contendo o horário de efetiva permanência no consultório e em relação ao acompanhante, emitir uma declaração de acompanhamento, também no horário em que esteve presente no consultório. O código referente à Classificação Internacional de Doenças (CID) só deve ser colocado a pedido do paciente, sendo este pedido documentado na segunda via do atestado (via que fica no prontuário). Porém, caso o pai tenha a necessidade de justificar sua ausência no trabalho, pode ser que a empresa solicite para ele o atestado e nada impede a concessão do documento a ambos. Assim sendo, as respostas que afirmavam que a conduta seria a de emitir atestado para ambos ou apenas para o menor, com declaração ao acompanhante, 
classificaram-se como ideal. Aquelas que descreviam o fornecimento de declaração para ambos, agruparam-se como aceita, enquanto as respostas diferentes dessas opções determinaram-se como não recomendada.

\section{Conclusão}

A conduta profissional avaliada em relação as situações problemas relacionadas ao exercício ético e legal da Odontologia se mostrou bem variada. A resposta considerada ideal prevaleceu em apenas 4 situações problemas, sendo a conduta diante da extração de um dente errado, diante da fratura de uma lima no canal radicular, diante de um processo com inversão de ônus da prova e sobre a possibilidade do clínico geral executar procedimento de especialidades. Nas análises de associação verificou-se melhor desempenho de mulheres, vinculados ou egressos de instituição pública e com idade acima de 22 anos. Ficou evidente que, na amostra considerada, não há uma padronização de conduta relacionada ao exercício ético e legal da Odontologia.

Trata-se de um tema de extrema importância uma vez que os profissionais, a cada dia mais, vivenciam indagações em relação aos aspectos éticos e legais. Desta forma, estudos futuros poderão explorar e aprofundar mais a temática dada a variabilidade de respostas e posicionamentos diferentes dos dentistas diante das situações problema apontadas neste estudo.

\section{Referências}

Almeida, C. A. P. (2004). Prontuário odontológico - Uma orientação para o cumprimento da exigência contida no inciso VIII do art. 5 do código de ética odontológica. Conselho Federal de Odontologia, Rio de Janeiro.

Amorim, A. G. \& Souza, E. C. F. (2010). Problemas éticos vivenciados por dentistas: dialogando com a bioética para ampliar o olhar sobre o cotidiano da prática profissional. Ciência \& Saúde Coletiva, 15(3), 869-978.

Ayres, M., Junior, M., Ayres, D. L., \& Dos Santos, A. A. (2007). BIOESTAT-aplicações estatísticas nas áreas das Ciências Bio-Médicas.

Batista, A. U. D. \& Castro, R. D. (2019). Métodos e técnicas de pesquisa aplicadas à odontologia. Editora UFPB. 206p.

Brasil. Lei n 5.081, de 24 de agosto de 1966. Regula o exercício da Odontologia. Diário Oficial, Brasília.

Brasil. Decreto-lei no 2.848, de 7 de dezembro de 1940. Código Penal Brasileiro. Diário Oficial da União, Brasília, DF.

Brasil. Lei $n^{\circ}$ 6. 259, de 30 de outubro de 1975. Dispõe sobre a organização das ações de Vigilância Epidemiológica, sobre o Programa Nacional de Imunizações, estabelece normas relativas à notificação compulsória de doenças, e dá outras providências. Diário Oficial, Brasília.

Brasil. Lei no 10.406, de 10 de janeiro de 2002. Institui o Código Civil. Diário Oficial da União, Brasília, DF.

Brasil. Lei nº 8.078 , de 11 de setembro de 1990. Código de defesa do Consumidor. Dispõe sobre a proteção do consumidor e dá outras providências. Diário Oficial da União, Brasília, DF, 12 set. 1990.

Brasil. Ministério da Saúde. Portaria de Consolidação $n^{\circ}$ 4, de 28 de setembro de 2017. Consolidação das normas sobre os sistemas e os subsistemas do Sistema Único de Saúde. Diário Oficial, Brasília.

Brasil. Resolução n 3, de 21 de junho de 2021. Diretrizes Curriculares Nacionais do curso de graduação em Odontologia e dá outras providências. Diário Oficial da União, Brasília, DF.

Brites, A. N., Pithan, S. A., Nunes, M. F., \& Brites, I. F. (2016). Odontologia Legal no ensino superior do Estado do Rio Grande do Sul. Revista da ABENO, $6(3): 36-45$

Conselho Federal de Odontologia. Resolução no 118 , de 11 de maio de 2012. Revoga o Código de Ética Odontológica aprovado pela Resolução CFO-42/2003 e aprova outro em substituição. Diário Oficial da União, Brasília, DF, 11 de maio de 2012. Seção 1, p. 118.

Couto, R. C. (2011). Perícias em Medicina e Odontologia Legal. Rio de Janeiro: MedBook.

Daruge, E., Júnior, E. D., \& Júnior, L. F. Tratado de odontologia legal e deontologia. Guanabara Koogan, 2017.

Dean, A.G., Dean, J. A., Coulombier, D., Brendel, K. A., Smith, D. C., \& Burton, A. H. (2002). Epi-Info: A Word Processing, Database, and Statistics Program for Epidemiology on Microcomputers. Atlanta: Centers of Disease Control and Prevention.

Estrela, C. (2018). Metodologia científica: ciência, ensino, pesquisa. (3a ed.), Artes Médicas, 707 p.

França, B. H. S. (2007). Atestados odontológicos: cuidados na redação. Rev. Clin. Ortodont. Dental Press, 6(3):44-45.

Júnior, A. P. (2015). Manual de Direito Civil. Editora Saraiva. 
Research, Society and Development, v. 11, n. 3, e21911326384, 2022

(CC BY 4.0) | ISSN 2525-3409 | DOI: http://dx.doi.org/10.33448/rsd-v11i3.26384

Lolli, L. F., Lolli, M. C. G. S., Marson, F. C., Oliveira \& Silva, C., Moreira, M. A., \& Silva, R. H. A. (2013). Responsabilidade criminal do cirurgião-dentista. Brazilian Journal of Surgery and Clinical Research - BJSCR, 1(1):17-23.

Marconi, M. A. \& Lakatos, E. M. (2021). Fundamentos de metodologia cientifica. (9a ed.), Atlas.

Nogueira, T. H., Campos \& Santos, C., Petroski, T. C. A., Galvão, A. P. B., Filho, M. A. N., Lolli, M. C. G. S., \& Lolli, L. F. (2014). A responsabilidade profissional do cirurgião dentista docente. Brazilian Journal of Surgery and Clinical Research - BJSCR, 8(3):84-91.

Paranhos, L. R., Salazar, M., Ramos, A. L., \& Siqueira, D. F. (2007). Orientações legais aos cirurgiões-dentistas. Revista Odonto, jul-dez, 15(30).

Pereira, A. S., Shitsuka, D. M., Parreira, F. J., \& Shitsuka, R. (2018). Metodologia da pesquisa científica. UFSM.

Peres, A. S., Peres, S. H. C. S., Nishida, C. L., Grandizoni, D. K., Ribeiro, I. W. J., Gobbo, L. G., \& Poleti, M. L. (2007). Peritos e Perícias em Odontologia. Revista de Odontologia da Universidade Cidade de São Paulo, set-dez, 19(03):320-4.

Prodanov, C. C., \& Freitas, E. C. de. (2013). Metodologia do trabalho científico: métodos e técnicas da pesquisa e do trabalho acadêmico. (2a ed.) Feevale.

Schwartz, S. Endodontics and the law: an interview with Dr. Stephen Schwartz. Interview by Philip Bonner. (1995). Dent Today.; 14(5):54-57.

Silva, G. M. C., Veltrini, V. C., Santos, G. L., Silva, I. R. G., Lolli, L. F., \& Fujimaki, M. (2021). Caracterização dos cursos de harmonização orofacial ofertados em um município do estado do Paraná. Research, Society and Development, 10(17).

Silva, M. (1997). Compêndio de Odontologia legal. Medsi.

Silva, R. H. A. (2010). Orientação Profissional para Cirurgião-dentista: ética e legislação. Santos.

Silva, R. H. A., Musse, J. O., Melani, R. F. H., \& Oliveira, R. N. (2009). Responsabilidade civil do cirurgião-dentista: a importância do assistente técnico. Rev Dental Press Ortodon Ortop Facial. 14(6): 65-71, nov./dez.

Vanrell, J. P. 2019. Odontologia Legal e Antropologia Forense: (3a ed.), Guanabara Koogan. 